\title{
Implementasi Metode Pengembangan Sistem Extreme Programming (XP) pada Aplikasi Investasi Peternakan
}

\author{
Rohmat Indra Borman ${ }^{\mathrm{a} 1}$, Adhie Thyo Priandika ${ }^{\mathrm{a} 2}$, Arif Rahman Edison ${ }^{\mathrm{a} 3}$ \\ ${ }^{a}$ Fakultas Teknik dan Ilmu Komputer (FTIK), Universitas Teknokrat Indonesia \\ Jl. Z. A. Pagar Alam No.9 -11, Labuhan Ratu, Kedaton, Kota Bandar Lampung, Lampung, 35132, Indonesia \\ ${ }^{1}$ rohmat indra@teknokrat.ac.id \\ ${ }^{2}$ adhie thyo@teknokrat.ac.id \\ ${ }^{3}$ arifrăhmanedison@gmail.com
}

\begin{abstract}
Abstrak
Sektor peternakan merupakan motor penggerak pembangunan khususnya di wilayah pedesaan. Salah satu permasalahan yang dihadapi oleh peternak di Indonesia terutama pada peternak skala ekonomi kecil adalah permodalan yang terbatas. Untuk mengatasi hal tersebut maka dibutuhkan cara untuk mendapatkan modal. Pada penelitian ini akan dikembangkan aplikasi investasi peternakan online dengan menerapkan metode pengembangan sistem extreme programming (XP) yang mempermudah peternak menemukan investor dan mempermudah investor dalam mencari tempat investasi khususnya dibidang peternakan. Metode extreme programming (XP) menawarkan tahapan dalam waktu relatif singkat sesuai dengan fokus yang akan dicapai pengembang. Berdasarkan pengujian usability, aplikasi investasi peternakan menunjukan nilai rata-rata 88\% dalam kategori baik, sehingga aplikasi layak untuk digunakan.
\end{abstract}

Kata kunci: aplikasi, extreme programming, investasi, peternakan

\section{Implementation of Extreme Programming (XP) System Development Method in Livestock Investment Aplication}

\begin{abstract}
The livestock sector is the driving force of development, especially in rural areas. One of the problems faced by farmers in Indonesia, especially in small-scale farmers, is limited capital. To overcome this, we need a way to get capital. In this research an online livestock investment application will be developed by applying the extreme programming (XP) system development method that makes it easy for farmers to find investors and makes it easier for investors to find investment sites, especially in the livestock sector. The extreme programming (XP) method offers stages in a relatively short time in accordance with the focus that will be achieved by the developer. Based on usability testing, farm investment applications show an average value of $88 \%$ in the good category, so the application is feasible to use.
\end{abstract}

Keywords: application, extreme programming, investment, livestock

\section{Pendahuluan}

Berdasarkan data, kontribusi sub sektor peternakan pada Produk Domestik Bruto (PDB) nasional tahun 2017 adalah sebesar $1,57 \%$ dan berkontribusi sebesar $15,87 \%$ [1]. Setiap tahunnya permintaan akan hasil produksi ternak terus mengalami peningkatan akan tetapi kemampuan peternak lokal dalam mencukupi permintaan konsumsi dinilai masih belum cukup. Konsumsi daging sapi pada tahun 2016 meningkat sebesar 3,21\%, konsumsi telur ayam ras meningkat sebesar $2,46 \%$ dan konsumsi susu olahan cair menignkat sebesar 24,43\% [2]. Faktor lambannya perkembangan peternakan di Indonesia didominasi oleh peternak kecil yang belum optimal dalam permodalan dan penguasaan teknologi. Kondisi peternakan dihadapkan pada permasalahan teknologi budidaya yang sederhana, serta permodalan yang terbatas [3]. Salah satu cara mendapatkan modal adalah melalui investasi. Investasi dapat diartikan sebagai penanaman uang dengan harapan mendapatkan keuntungan dimasa yang akan datang [4]. Investasi merupakan start awal dari sebuah kegiatan produksi dan sebagai salah satu faktor dalam meningkatkan pertumbuhan ekonomi [5]. Dalam Investasi dibutuhkan komitmen untuk menahan sejumlah dana, hal ini memiliki tujuan untuk mendapatkan sejumlah keuntungan dimasa yang akan datang [6]. Untuk mempertemukan antara investor dengan peternak maka dibutuhkan teknologi yang dapat menghubunkan keduanya sehingga dapat terjalin proses investasi dalam bidang peternakan. 
Untuk mengembangkan sebuah software dibutuhkan tahapan yang dilakukan dengan matang dan terencana. Maka diperlukan metodologi pengembangan sistem untuk merencanakan pengembangan sistem yang sesuai dengan kasus yang dihadapi dalam pengembangan sistem. Metodologi pengembengan sistem merupakan kerangka yang menjadi pijakan dalam perancangan dan pengembangan perangkat lunak dengan tujuan menghasilkan aplikasi yang sesuai dengan kebutuhan bisnis sebuah organisasi [7]. Terdapat beberapa metodologi pengembangan software yang dapat digunakan, seperti prototype, waterfall, RAD, dan agile development [8]. Pendekatan agile development telah diperkenalkan sebagai upaya untuk membuat rekayasa perangkat lunak yang fleksibel dan efisien. Agile software development merupakan metodologi pengembangan perangkat lunak yang berbasis pada pengembangan iteratif, di mana persyaratan setiap tahapan dan solusi yang ditawarkan berkembang dengan pendekatan kolaborasi antar tim yang terorganisir [9]. Salah satu cabang metode agile development yang digunakan untuk menyesuaikan kebutuhan pengembangan adalah extreme programming (XP). XP merupakan pengembangan rekayasa perangkat lunak yang dapat digunakan untuk pengembangan sistem dengan requirement yang tidak jelas maupun terjadi perubahan terhadap requirement yang sangat cepat [10].

Dari beberapa penelitian sebelumnya, penerapan metode pengembangan sistem XP telah bekerja dengan baik. Penelitian tentang penerapan metode extreme programming (XP) dalam perancangan aplikasi perhitungan kuota SKS mengajar dosen [10], pada hasil pengujian black box testing menununjuukan bahwa aplikasi telah sesuai dengan kebutuhuan. Tahapan dalam XP telah membantu dalam menghasilkan aplikasi yang sesuai dengan fungsional requirement. Penelitian lain, tentang extreme programming (XP) untuk rancang bangun aplikasi pengelolaan surat keterangan kependudukan [11], menunjukkan bahwa metode XP dapat diterapkan dalam membangun aplikasi sederhana yang tidak memerlukan tahapan pengulangan perangkat lunak dan berdasarkan pengujian black-box testing didapat bahwa XP menghasilkan aplikasi yang sesuai dengan kebutuhan. Selanjutnya, penelitian tentang pendekatan metodologi extreme programming (XP) pada aplikasi e-commerce berbasis $m$-commerce [12], memperlihatkan bahwa teknik pendekatan menggunakan metode XP dalam tahap perancangan aplikasi memberikan percepatan perencanaan pada setiap perubahan kebutuhan fungsi-fungsi yang diinginkan oleh klien dengan tanpa batasan. Dari beberapa penelitian sebelumnya menunjukkan bahwa metode pengembangan sistem XP mampu menghasilkan aplikasi yang sesuai dengan kebutuhan, karena melalui tahapan yang iteratif dan inkremental. Pada penelitian ini akan dikembangkan aplikasi investasi peternakan online dengan menerapkan metode pengembangan sistem extreme programming (XP) yang mempermudah peternak menemukan investor dan mempermudah investor dalam mencari tempat investasi khususnya dibidang peternakan.

\section{MetODOLOGI}

Penelitian ini mengacu pada metodologi pengembangan sistem Extreme Programming (XP). Extreme programming (XP) adalah metodologi dalam pengembangan agile software development methodologies yang berfokus pada pengkodean (coding) yang menjadi aktivitas utama dalam semua tahapan pada siklus pengembangan perangkat lunak [13]. Metode XP merupakan metode yang responsif terhadap perubahan [14]. Dalam XP terdapat iterasi yang bisa dilakukan berulang kali sesuai dengan kebutuhan. XP menawarkan tahapan dalam waktu yang singkat dan berulang untuk bagian-bagian yang berbeda sesuai dengan fokus yang akan dicapai. Tahapan pengembangan perangkat lunak dengan XP meliputi: planning (perencanaan), design (perancangan), coding (pengkodean) dan testing (pengujian) [15]. Tahapan-tahapan XP dapat dilihat pada gambar 1 berikut ini.

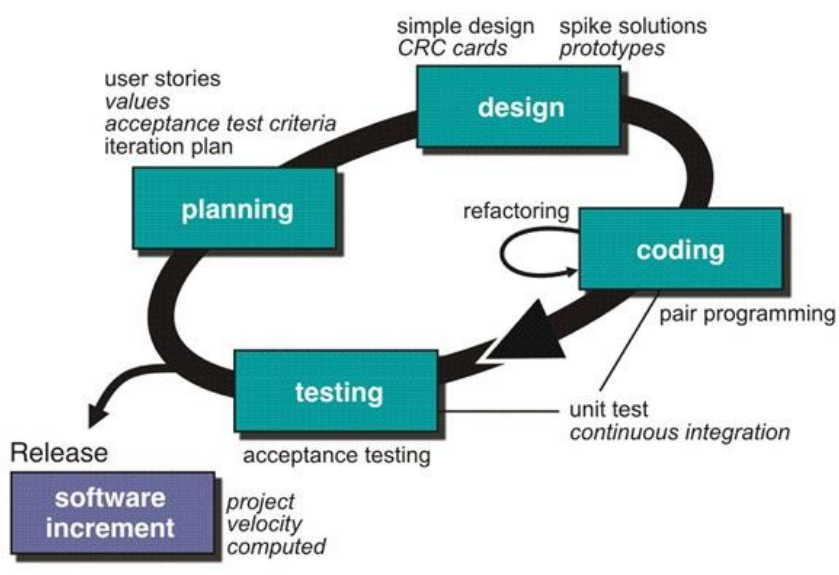

Gambar 1. Fase pada extreme programming (XP)

Berdasakan gambar 1 diatas, maka fase dalam metodologi pengembangan sistem XP adalah sebagai berikut :

1) Planning (Perencanaan): Tahap perencanaan dimulai dengan pemahaman konteks bisnis dari aplikasi, mendefinisikan output, fitur yang ada pada aplikasi, fungsi dari aplikasi yang dibuat, serta alur pengembangan aplikasi [15]. Dapat dikatakan bahwa tahapan ini menentukan fungsionalitas keseluruhan yang akan dikembangkan dalam sistem [11].

2) Design (Perancangan): Pada tahap fokus pada design aplikasi secara sederhana, alat untuk mendesign pada tahap ini dapat menggunakan CRC (Class Responsibility Collaborator) [15]. CRC memetakan kelaskelas yang akan dibangun dalam use case diagram, class diagram dan activity diagram.

3) Coding (Pengkodean): Coding atau pengkodean merupakan penerjemahan dari perancangan dalam bahasa pemrograman yang dikenali oleh komputer [16]. Pada penelitian ini aplikasi dibagi menjadi dua, yaitu untuk front-end dan back-end. Pengkodean dengan menggunakan baahasa pemrograman PHP dengan compailer Sublime Text 3 dan database MySQL. 
4) Testing (Pengujian): Sistem yang telah dibangn harus diuji terlebih dahulu agar dapat menemukan kesalahan - kesalahan [17]. Pada penelitian ini menggunakan pengujian terhadap usability, dimana pengujian dilakukan untuk mengetahui pengguna apakah dapat mempelajari dan menggunakan produk untuk mencapai tujuannya dan seberapa kepuasaan pengguna terhadap penggunaan aplikasi serta kegunaanya [18].

\section{HASIL DAN PEMBAHASAN}

Rancang bangun aplikasi investasi peternakan dikembangkan dengan metodologi XP, berikut ini hasil dari setiap tahapan yang telah dilakukan.

\section{A. Planning (Perencanaan)}

Kegiatan perencanaan dimulai dengan mendengarkan pelanggan melalui wawancara, hal itu bertujuan untuk mengumpulkan informasi mengenai kebutuhan sistem yang akan dibangun sehingga dapat diketahui konteks bisnis dari sistem yang akan dibangun. Hasil dari mendengarkan pelanggan kemudian disusun dalam bentuk analisa kebutuhan fungsional. Kebutuhan fungsional diperlukan untuk mengetahui proses apa saja yang dapat dilakukan oleh sistem, serta siapa saja yang dapat menggunakan sistem yang dibangun [19]. Berikut ini kebutuhan fungsional dari sistem yang akan dikembangkan: 1. Investor

a. Investor dapat mendaftarkan diri terlebih dahulu pada form pendaftaran sebelum memilih sebuah proyek, investor harus mengisi setiap kolom yang ada secara benar agar dapat memiliki akun

b. Investor dapat masuk kedalam sistem melalui form login investor dengan memasukan alamat email dan password yang sudah terdaftar.

c. Investor dapat melihat daftar proyek yang bisa di investasikan, sehingga para investor dapat melakukan investasi dengan nominal minimum 10 ribu rupiah.

d. Investor dapat melihat rincian proyek investasi yang sudah di inputkan oleh peternak berupa perjanjian proyek, dana yang dibutuhkan, dan lainlain.

e. Investor dapat memantau proyek untuk melihat perkembangan proyek yang sudah di investasikan.

f. Investor dapat melakukan tarik keuntungan (withdraw) yang dihasilkan oleh proyek investasi berdasarkan besaran persentase keuntungan yang nantinya akan masuk ke rekening investor.

2. Peternak

a. Peternak dapat mendaftarkan diri melalui form pendaftaran sebelum memilih sebuah proyek, peternak harus mengisi setiap kolom yang ada secara benar agar dapat memiliki akun

b. Peternak dapat masuk kedalam sistem melalui form login peternak dengan memasukan alamat email dan password yang sudah terdaftar.

c. Peternak dapat membuat proyek investasi peternakan dengan mencantumkan foto usaha, foto surat ijin usaha, nomor rekening, besaran penghasilan, dana yang dibutuhkan, dan persentase bagi hasil. d. Peternak dapat membuat rincian proyek berupa perjanjian proyek, dana yang dibutuhkan, dan lainlain.

e. Peternak dapat menarik modal usaha proyek yang sudah di investasikan oleh para investor yang nantinya akan dikirmkan ke nomor rekening peternak.

f. Peternak dapat mengirimkan total seluruh keuntungan yang sudah dihasilkan dari proyek usaha yang nantinya system secara otomatis akan membagikan total seluruh keuntungan tersebut kepada para investor.

\section{B. Design (Perancangan)}

Dalam metode pengembangan sistem extreme programming (XP) desain sistem dilakukan dengan menggunakan Class Responsibility Collaborator (CRC). CRC bertujuan untuk membangun kelas-kelas yang akan di gunakan. Berikut ini desain CRC yang dikembangakan pada sistem :

1) Fungsi dari aplikasi: mendiskrupsikan kegunaan aplikasi bagi user dan client. Berikut ini adalah fungsi aplikasi investasi peternakan.

TABEL I

CRC FUNGSI APLIKASI

\begin{tabular}{|c|c|}
\hline NAMA DOKUMEN & FUNGSI APLIKASI USER \\
\hline Nama aplikasi & Aplikasi Investasi Peternakan \\
\hline Nama klien & Peternak dan Investor \\
\hline Kegiatan & Fungsi dari aplikasi \\
\hline Pelaksanaan & 1 Oktober 2019 s/d 23 Desember 2019 \\
\hline No & Deskripsi aplikasi yang dibuat \\
\hline 1. & $\begin{array}{l}\text { Fungsi dari pengembangan aplikasi } \\
\text { investasi peternakan adalah: } \\
\text { 1) Mempermudah peternak dalam } \\
\text { mencari modal } \\
\text { 2) Mempermudah investor untuk } \\
\text { menginvestasikan dana sesuai } \\
\text { dengan keinginan }\end{array}$ \\
\hline
\end{tabular}

2) Menetukan waktu: Pada tahap ini devloper melakukan estimasi waktu dalam pengembangan sistem.

TABEL II

CRC JADWAL PELAKSANAAN

\begin{tabular}{|c|c|c|c|c|c|c|c|c|c|c|c|c|}
\hline $\begin{array}{c}\text { NAMA } \\
\text { DOKUMEN }\end{array}$ & \multicolumn{12}{|c|}{ WAKTU } \\
\hline $\begin{array}{l}\text { Nama } \\
\text { aplikasi }\end{array}$ & \multicolumn{12}{|c|}{ Aplikasi Investasi Peternakan } \\
\hline Nama klien & \multicolumn{12}{|c|}{ Peternak dan Investor } \\
\hline Kegiatan & \multicolumn{12}{|c|}{ Fungsi dari aplikasi } \\
\hline Pelaksanaan & \multicolumn{12}{|c|}{1 Oktober $2019 \mathrm{~s} / \mathrm{d} 23$ Desember 2019} \\
\hline No & \multicolumn{12}{|c|}{ Deskripsi aplikasi yang dibuat } \\
\hline \multirow[t]{4}{*}{1.} & \multicolumn{12}{|c|}{$\begin{array}{l}\text { Waktu pembuatan aplikasi selama } 3 \text { bulan } \\
\text { Tahun } 2019\end{array}$} \\
\hline & \multicolumn{4}{|c|}{ Oktober } & \multicolumn{4}{|c|}{ November } & \multicolumn{4}{|c|}{ Desember } \\
\hline & 1 & 2 & 3 & 4 & 1 & 2 & 3 & 4 & 1 & 2 & 3 & 4 \\
\hline & : & 它苞 & $\begin{array}{l}\overline{\tilde{w}} \\
\stackrel{\widetilde{n}}{ \pm}\end{array}$ & 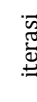 & 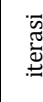 & 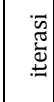 & 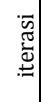 & 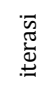 & "י & 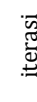 & 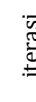 & $\overline{\underline{n}}$ \\
\hline
\end{tabular}


Selanjutnya aplikasi didesain dengan menggunakan use case diagram. Use case digambarkan secara tekstual ke bentuk use case scenario yang bertujuan untuk menjelaskan interaksi antara aktor dengan sistem, kemudian diilustrasikan dalam bentuk use case diagram untuk menggambarkan konteks dari sistem yang dikembangkan [20]. Use case diagram menggambarkan fungsional yang diharapkan dari sebuah sistem [21]. Desain use case diagram dapat dilihat pada gambar 2 berikut ini.

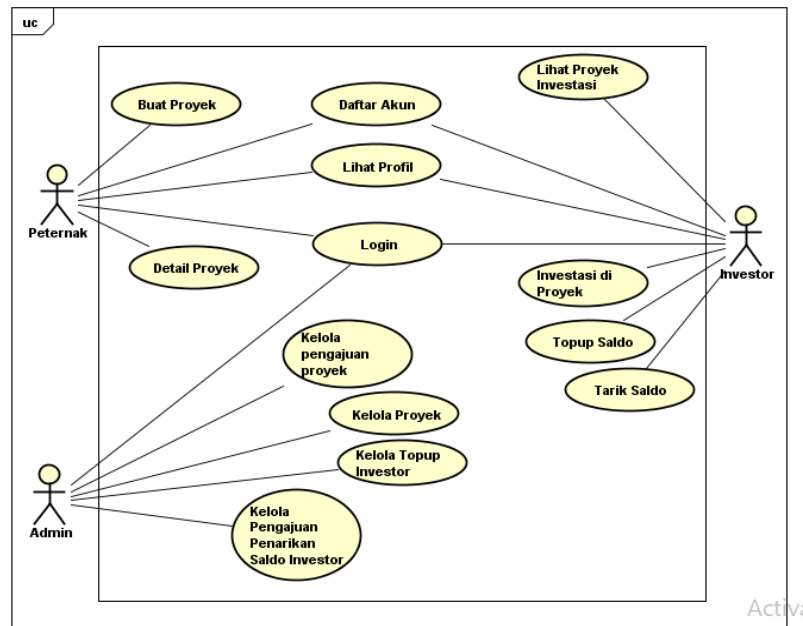

Gambar 2. Use case diagram aplikasi investasi peternakan

\section{Coding (Pengkodean)}

Setelah dilakukan perancangan, selanjutnya diimplementasikan dalam bentuk kode program. Pengkodean dengan menggunakan baahasa pemrograman PHP dengan compailer Sublime Text 3 dan database MySQL. Sesuai dengan fungsional yang telah ditetapkan, sebelum dapat menggunakan aplikasi investor dan peternak harus melakukan pendaftaran. Setelah melakukan pendaftaran peternak dan investor dapat melakukan login kedalam aplikasi.

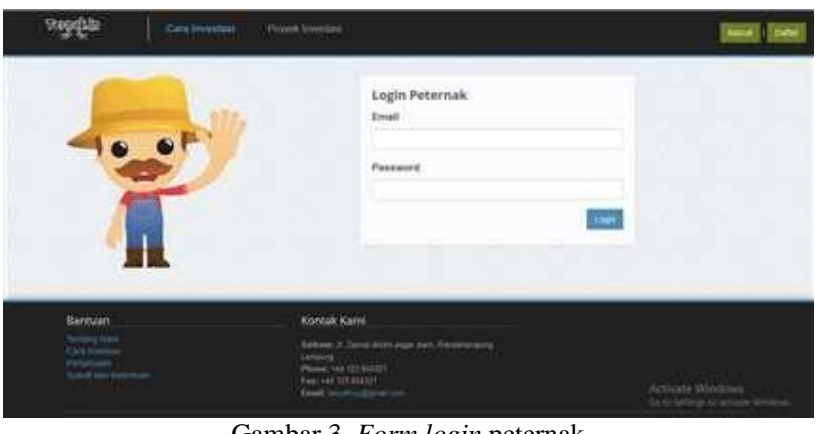

Gambar 3. Form login peternak

Setelah dapat login, baik peternak maupun investor akan masuk ke Dashboard masing-masing. Pada dashboard peternak, peternak dapat memilih menu buat proyek, melihat list proyek yang dimiliki, serta tampilan profil peternak. Sedangkan pada dashbord investor, investor menu wallet, melihat list proyek yang di investasikan, serta tampilan profil investor. Untuk peternak dapat buat proyek baru melalui Form Buat Proyek yang berfungsi untuk peternak dalam mengajukan proyek investasinya. Kemudian peternak juga dapat melihat detail detail proyek yang dimilik peternak. Pada halaman ini peternak dapat melihat apakah proyeknya sudah disetujui, melihat perkembangan penggalangan dana, dan investor yang menanamkan modal di proyeknya.

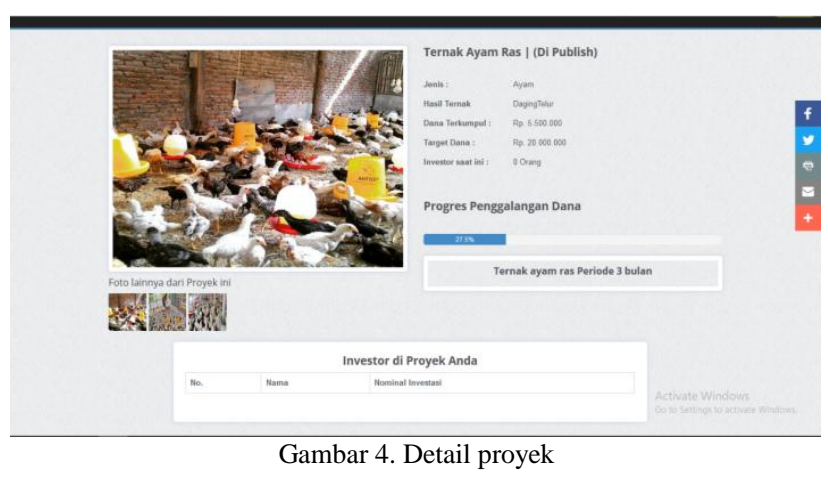

Untuk mempermudah investor dalam transaksi, investor dapat menggunakan fasilitas e-money yang digunakan dalam transaksi atau investasi yaitu Wallet Investor. Pada halaman ini terdapat informasi riwayat topup (isi saldo) yang telah dilakukan, melihat detail top-up serta melakukan top-up saldo.

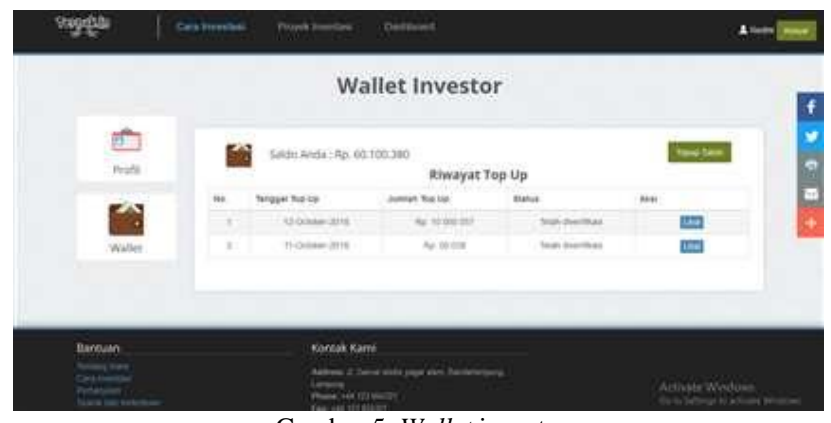

Gambar 5. Wallet investor

Untuk melakukan investasi, investor dapat melakukan pada halaman menu Proyek Investasi. Halaman ini berisi proyek proyek yang dapat di investasikan. Investor juga dapat melihat detail informasi dari investasi-investasi yang ditawarkan dengan mengklik salah satu proyek investasi. Selain peternak dan investor terdapat juga user sebagai admin yang bertugas memvalidasi peternak ketika mendaftar, proyek yang ditawarkan dan membantu dalam memonitoring pelaksanaan proyek. Admin dapat melihat daftar proyek yang diajukan oleh peternak pada menu waiting list proyek. Admin dapat melakukan verivikasi dan validasi proyek melalui pengecekan kelengkapan data dan kebenaran data proyek yang diajukan untuk menghindari hal-hal yang tidak diinginkan. Admin dapat melakukan observasi lapangan terhadap peternak yang mengajukan proyek. Setelah proyek dinyatakan layak untuk diajukan kemudian admin memverifikasi dan memvalidasi proyek melalui sistem. 


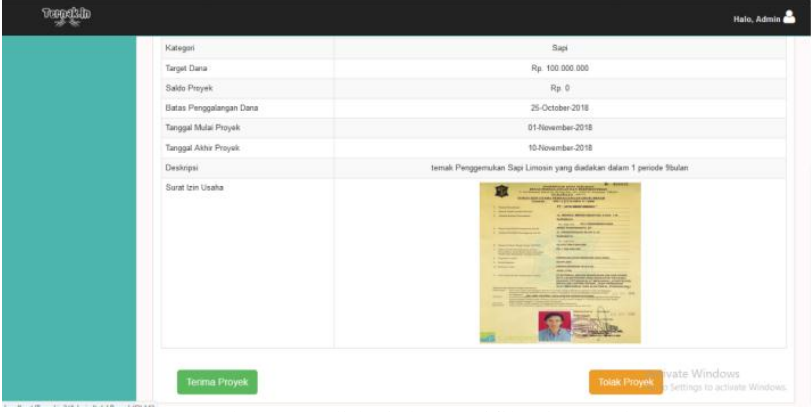

Gambar 6. Validasi dan verifikasi proyek

\section{Testing (Pengujian)}

Sebelum aplikasi digunakan oleh masyarakat, dilakukan pengujian berdasarkan usability testing. Usabiltiy merupakan salah satu aspek kualitas perangkat lunak Berdasarkan ISO 9126. ISO 9126 merupakan model yang digunakan untuk mengevaluasi kualitas software dengan tujuan untuk memberikan standar baku dalam proyek perangkat lunak [22]. Pada aspek Usability terdapat 4 sub-kriteria yaitu: understandbility (dapat dimengerti); learnbility (dapat dipelajari); operability (pengoperasian); attractiveness (daya tarik) [23]. Dari 4 sub-kriteria tersebut terdapat 10 butir pertanyaan dalam bantuk kuesioner. Kuesioner dibuat dengan menggunakan skala guttman, dimana pernyataan tertentu bersifat lebih ekstrem dibandingkan pernyataan yang lain atau dalam kata lain hanya ada dua jawaban yaitu setuju dan tidak setuju [24]. Kuesioner disebar kepada 100 responden yang terdiri dari 50 peternak dan 50 masyarakat umum. Berikut hasil dari pengujian usability testing.

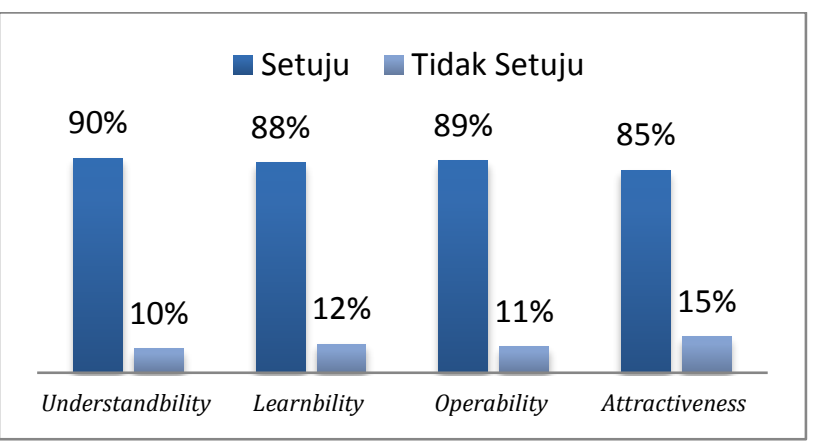

Gambar 7. Hasil pengujian usability

Dari hasil pengujian usability dengan menggunakan kuesioner menunjukan nilai rata-rata terhadap usability atau kemudahan dalam penggunaan adalah $88 \%$ dalam kategori baik. Dengan kriteria klasifikasi persentase sebagaia berikut : Baik, dengan nilai 76\%-100\%; Cukup, dengan nilai 56\%-75\%; Kurang Baik, dengan nilai 40\%$55 \%$, sedangkan Tidak Baik, memiliki nilai kurang dari $40 \%$ [25].

\section{KESIMPULAN}

Berdasarkan penelitian yang telah dilakukan, dapat diambil kesimpulan bahwa metode extreme programming (XP) menghasilkan software dengan waktu yang singkat dan menghasilkan software yang sesuai dengan kebutuhan. XP mampu menghasilkan software selama 3 bulan, sesuai dengan perencanaan jadwal pelaksanaan pada Class Responsibility Collaborator (CRC) yang telah dibuat.
Selain itu, aplikasi investasi peternakan online dengan menggunakan XP dapat diterima oleh user, karena berdasarkan pengujian usability menunjukan nilai rata-rata $88 \%$ dalam kategori baik, sehingga aplikasi layak untuk digunakan dan sesuai kebutuhan.

\section{UCAPAN TERIMA KASIH}

Peneliti menugucapkan terima kasih kepada Kemenristek/BRIN atas Hibah skema Penelitian Dosen Pemula (PDP) dan LPPM Universitas Teknokrat Indonesia yang telah memberikan dukungan terhadap penelitian ini.

\section{DAFTAR PUSTAKA}

[1] G. Hartomo, "Peternakan Jadi Kunci Penting Perekonomian Indonesia, Ini Penjelasannya," Economy.Okezone.Com, 2018 [Online]. Available: https://economy.okezone.com/read/2018/07/04/320/1917701/peter nakan-jadi-kunci-penting-perekonomian-indonesia-inipenjelasannya.

[2] Direktorat Jenderal Peternakan dan Kesehatan Hewan, "Konsumsi Periode Tahun 2016," Sekretariat dirjen PKH, 2017. [Online]. Available:

https://ditjenpkh.pertanian.go.id/userfiles/File/Konsumsi1_Periode 2016.pdf?time $=1501058657531$

[3] Z. Zakiah, A. Saleh, and K. Matindas, "Gaya Kepemimpinan dan Perilaku Komunikasi GPPT dengan Kapasitas Kelembagaan Sekolah Peternakan Rakyat di Kabupaten Muara Enim,” J. Penyul., vol. 13, no. 2, pp. 133-142, 2017.

[4] Mudjiyono, "Pengertian Investasi," J. STIE Semarang, vol. 4, no. 2, pp. 1-18, 2012

[5] M. Sari, M. N. Syechalad, and A. S. Majid, "Pengaruh Investasi, Tenaga Kerja Dan Pengeluaran Pemerintah Terhadap Pertumbuhan Ekonomi Di Indonesia," J. Ekon. dan Kebijak. Publik Indones., vol. 3, no. 2, pp. 109-115, 2016.

[6] E. Pardiansyah, "Investasi dalam Perspektif Ekonomi Islam: Pendekatan Teoritis dan Empiris," Econ. J. Ekon. Islam, vol. 8, no. 2 , p. 337,2017

[7] A. Fatoni and D. Dwi, "Rancang Bangun Sistem Extreme Programming Sebagai Metodologi Pengembangan Sistem,' Prosisko, vol. 3, no. 1, pp. 1-4, 2016.

[8] K. C. Dewi, P. I. Ciptayani, and I. W. R. Wijaya, “Agile Project Management Pada Pengembangan E-Musrenbang Kelurahan Benoa Bali Agile Project Management On E-Musrenbang Development In Benoa Village Bali," J. Teknol. Inf. dan Ilmu Komput., vol. 5, no. 6, pp. 723-730, 2018.

[9] I. Mahendra and D. T. E. Yanto, “Agile Development Methods Dalam Pengembangan Sistem Informasi Pengajuan Kredit Berbasis Web (Studi Kasus : Bank Bri Unit Kolonel Sugiono)," J. Teknol. Dan Open Source, vol. 1, no. 2, pp. 13-24, 2018.

[10] I. Carolina and A. Supriyatna, "Penerapan Metode Extreme Programming Dalam Perancangan Aplikasi Perhitungan Kuota SKS Mengajar Dosen," J. Khatulistiwa Inform., vol. 3, no. 1, pp. 106-113, 2019

[11] L. Rusdiana, "Extreme Programming untuk rancang bangun aplikasi pengelolaan surat keterangan kependudukan," Regist. $J$. Ilm. Teknol. Sist. Inf., vol. 4, no. 1, p. 49, 2018.

[12] E. B. Pratama, "Pendekatan Metodologi Extreme Programming pada Aplikasi e-Commerce Berbasis M-Commerce Studi Kasus: Toko Buku An’Nur di Pontianak," J. Khatulistiwa Inform., vol. V, no. 2, pp. 92-102, 2017.

[13] T. Gumelar, R. Astuti, and A. T. Sunarni, "Sistem Penjualan Online Dengan Metode Extreme Programming," J. Telemat., vol. 9, no. 2, pp. 87-90, 2017.

[14] F. Sulianta, Strategi Merancang Arsitektur Sistem Informasi Masa Kini. Jakarta: PT. Elex Media Komputindo, 2019.

[15] I. G. N. Suryantara, "Merancang Applikasi dengan Metodologi Extreme Programming.” PT. Elex Media Komputindo, Jakarta, 2017

[16] M. Melinda, R. I. Borman, and E. R. Susanto, "Rancang Bangun Sistem Informasi Publik Berbasis Web (Studi Kasus : Desa Durian Kecamatan Padang Cermin Kabupaten Pesawaran)," J. Tekno Kompak, vol. 11, no. 1, p. 1, 2018. 
[17] A. E. Kumala, R. I. Borman, and P. Prasetyawan, "Sistem Informasi Monitoring Perkembangan Sapi Di Lokasi Uji Performance (Studi Kasus: Dinas Peternakan Dan Kesehatan Hewan Provinsi Lampung)," J. Tekno Kompak, vol. 12, no. 1, p. 5, 2018.

[18] M. I. Farouqi, I. Aknuranda, and A. D. Herlambang, "Evaluasi Usability Pada Aplikasi UBER Menggunakan Pengujian Usability,' J. Pengemb. Teknol. Inf. dan Ilmu Komput., vol. 2, no. 9, pp. 25992606, 2018.

[19] T. Monica and R. I. Borman, "Implementasi Konsep Media Sosial Dalam Sistem Informasi Kegiatan Kesiswaan (Studi Kasus : SMK XYZ)," J. Tekno Kompak, vol. 11, no. 2, p. 33, 2017.

[20] T. A. Kurniawan, "Pemodelan Use Case (UML): Evaluasi Terhadap beberapa Kesalahan dalam Praktik," J. Teknol. Inf. dan Ilmu Komput., vol. 5, no. 1, pp. 77-86, 2018.

[21] R. I. Borman and H. Fauzi, "Penerapan Metode Perbandingan Eksponensial (MPE) Dalam Sistem Pendukung Keputusan Penerimaan Beasiswa Siswa Berprestasi Pada SMK XYZ," CESS J. Comput. Eng. Syst. Sci., vol. 3, no. 1, pp. 17-22, 2018.

[22] Y. D. Nurseha and L. N. Pradany, "Survei Aplikasi E-learning untuk Mendukung Proses Belajar Mengajar pada Institusi Pendidikan Menggunakan Standar Kualitas ISO/IEC 9126," J. Ultim. InfoSys, vol. 5, no. 2, pp. 106-111, 2014.

[23] P. Botella et al., "ISO/IEC 9126 in practice: what do we need to know?," Softw. Meas. Eur. Forum 2004, pp. 297-306, 2004

[24] M. Morissan, Metode Penelitian Survei. Jakarta: PT. Fajar Interpratama Mandiri, 2012.

[25] M. H. Sayogo, "Penerapan Model Problem Based Learning Dalam Proses Pembelajaran Standar Kompetensi Mengukur Dengan Alat Ukur Mekanik Presisi Di Kelas X Smk Negeri Kudu Jombang," J. Pendidik. Tek. Mesin UNESA, vol. 5, no. 02, pp. 84-90, 2016. 